\title{
How Reliable Are Heat Pulse Velocity Methods for Estimating Tree Transpiration?
}

\author{
Michael A. Forster ${ }^{1,2}$ \\ 1 Edaphic Scientific Pty Ltd., Port Macquarie, NSW 2444, Australia; michael@edaphic.com.au \\ 2 School of Agriculture and Food Sciences, University of Queensland, St. Lucia, QLD 4072, Australia
}

Received: 11 August 2017; Accepted: 16 September 2017; Published: 18 September 2017

\begin{abstract}
Transpiration is a significant component of the hydrologic cycle and its accurate quantification is critical for modelling, industry, and policy decisions. Sap flow sensors provide a low cost and practical method to measure transpiration. Various methods to measure sap flow are available and a popular family of methods is known as heat pulse velocity (HPV). Theory on thermal conductance and convection, that underpins HPV methods, suggests transpiration can be directly estimated from sensor measurements without the need for laborious calibrations. To test this accuracy, transpiration estimated from HPV sensors is compared with an independent measure of plant water use such as a weighing lysimeter. A meta-analysis of the literature that explicitly tested the accuracy of a HPV sensors against an independent measure of transpiration was conducted. Data from linear regression analysis was collated where an $R^{2}$ of 1 indicates perfect precision and a slope of 1 of the linear regression curve indicates perfect accuracy. The average $R^{2}$ and slope from all studies was 0.822 and 0.860 , respectively. However, the overall error, or deviation from real transpiration values, was $34.706 \%$. The results indicate that HPV sensors are precise in correlating heat velocity with rates of transpiration, but poor in quantifying transpiration. Various sources of error in converting heat velocity into sap velocity and sap flow are discussed including probe misalignment, wound corrections, thermal diffusivity, stem water content, placement of sensors in sapwood, and scaling of point measurements to whole plants. Where whole plant water use or transpiration is required in a study, it is recommended that all sap flow sensors are calibrated against an independent measure of transpiration.
\end{abstract}

Keywords: meta-analysis; heat pulse velocity; sap flow; compensation heat pulse method; heat ratio method; T-max method; Sapflow+; transpiration

\section{Introduction}

Transpiration, the water loss from plants, is a significant component of the hydrologic cycle. Understanding transpiration is important for agriculture and horticulture, as well as modelling plant and ecosystem responses to climate change. Yet, a commonly used approach to estimate transpiration-sap flow methods-are usually inaccurate. Why these methods are inaccurate and how their accuracy can be improved is the focus of this review.

The quantity of water loss from plants is non-trivial and correlates to the size of a plant. Transpiration of corn, a $4 \mathrm{~m}$ tall Acacia tree, and a $60 \mathrm{~m}$ tall Eucalyptus tree is approximately 4, 10, and $800 \mathrm{~L}$ per day, respectively [1-3]. When these values are scaled to plots, forests or catchments, the amount of water loss is in the order of thousands to millions of liters. Such large numbers can significantly influence the interpretation of models as well as management or policy decisions. Therefore, it is important to know that transpiration measurements are accurate.

Various methods to measure transpiration in the field have long been employed and include weighing lysimeters [4], leaf or canopy conductance/resistance [5], and sap flow [6]. In practice, 
weighing lysimeters and canopy conductance instruments are expensive and impractical for any tree greater than a few meters in height. Leaf conductance instruments manually measure a small area of a single leaf and may not adequately capture spatial and temporal dynamics of whole tree water use. Sap flow sensors, on the other hand, provide a practical means to measure transpiration in trees [7].

Sap flow, in relation to transpiration, is the movement of fluid in the xylem of plants and is not to be confused with the sap in phloem. On short time scales of minutes to hours, sap flow can be directed towards physiological processes, such as stem water storage or photosynthesis in leaves, but over a longer time scale of one or several days approximately $99 \%$ is lost from the plant as transpiration [8]. Therefore, sap flow measurements are commonly used as a close approximation of transpiration.

There are various types of sap flow sensors, based on theoretical and empirical methods, but all of them rely on measuring temperature changes in the xylem following the application of heat $[7,9]$. Sap flow measurements are mostly conducted with sensors based on thermal dissipation, heat balance, or heat pulse velocity (HPV) methods [7]. The thermal dissipation and heat balance require continuous heat application to the plant and measure mass heat flow whereas HPV methods require a periodic pulse of heat and measure its velocity. Therefore, transpiration is estimated not on sap flow, per se, rather the transfer and movement of heat within the xylem.

Sap flow sensors are advantageous as they can potentially estimate transpiration without the need for sensor calibration. This is an advantage as many sensors can be deployed across disparate species, with varying anatomies, saving the time and expense of laborious calibrations. However, a significant amount of research has demonstrated that, despite careful installation and the inclusion of correction factors, sap flow sensors are not reliable in direct estimations of transpiration. This review focuses on a commonly used family of sap flow methods-heat pulse velocity (HPV) methods-to demonstrate the limitations of sap flow sensors, where inaccuracies lie, and possible mechanisms to improve sensor accuracy.

\section{Heat Pulse Velocity Methods}

HPV sensors are popular for sap flow measurements due to relatively low costs, low power requirements, and low maintenance [9]. A HPV sensor consists of a heater probe and one or more temperature probes inserted radially into the xylem. A heat pulse acts as a tracer within the sap stream, and temperature sensors measure change in temperature. Heat within the plant's xylem is transferred via conduction (i.e., thermal diffusivity/conductivity) or convection (i.e., sap movement or flow). HPV sensors only measure heat velocity and conversion factors are required to calculate sap velocity and sap flow.

Currently, there are seven known theoretical methods, and several empirical or dual methods, to determine HPV and sap flow. Four of the seven theoretical methods have been extensively tested and include the compensation heat pulse method (CHPM, [10]), heat ratio method (HRM, [11,12]), T-max method [13], and Sapflow + method [14]. The methods have been reviewed extensively elsewhere [9,12,15-18]. Briefly, following a heat pulse, the CHPM measures the time for temperatures to be equal in sensors installed upstream and downstream to the heater probe. The HRM measures the ratio of temperature rise in the downstream to upstream temperature probes $60 \mathrm{~s}$ following a heat pulse. The T-max method measures the time at which there is a maximum temperature rise in the downstream temperature probe following a heat pulse. The Sapflow+ method finds temperature changes in a downstream, upstream and tangential (adjacent) temperature probes following a heat pulse. Pearsall et al. [19] combined the CHPM and HRM methods into a Dual Heat Pulse Method.

\section{The Accuracy of HPV Sensors}

The accuracy of the four theoretical HPV methods, and one dual method, was assessed as part of this review. Researchers test the accuracy of HPV sensors against an independent method of measuring plant water use including weighing lysimeters (e.g., [14,19]), leaf or canopy gas exchange chambers 
(e.g., [20-22]), or potometers (e.g., [23,24]). Several published papers have tested the accuracy of HPV sensors and a meta-analysis of this literature was conducted.

Data was collated from every peer-reviewed published paper where the HPV sensor was tested against an independent measure of plant water use. In the literature, there were a variety of independent measures of plant water use including potometers, weighing lysimeters, leaf and canopy gas exchange, finite element modelling, and a stem heat balance sensor (Supplementary Materials). The studies listed in Supplementary Materials had the explicit aim to test the accuracy and precision of a HPV sensor or method. Therefore, it is assumed that the authors of the publications listed in Supplementary Materials tested the HPV sensor against an accurate independent measure of plant water use.

Data analysis in the literature was in the form of a linear regression analysis:

$$
y=\alpha+\beta x
$$

where the dependent variable $(y)$ is transpiration measured via HPV sensor, the independent variable $(x)$ is the independent method of measuring transpiration, $\beta$ is the slope and $\alpha$ is the intercept.

From each published result, the regression co-efficient $\left(R^{2}\right)$ and the slope $(\beta)$ of the linear regression curve was collated and analyzed for the meta-analysis. The $R^{2}$ is an indication of measurement precision; and $\beta$ is an indication of measurement bias where a slope of 1 indicates no bias, a slope $<1$ indicates an underestimation and a slope $>1$ indicates an overestimation of true plant water use. A third variable, deviation from slope, was determined by calculating the percent deviation of the observed slope from 1 . The deviation from slope indicates the overall accuracy of the method.

A summary of the results is presented in Table 1 and Figure 1. Complete results collated from the literature can be found in Supplementary Materials. Table 1 also presents the minimum and maximum measurement ranges for the respective HPV methods that was also collated from the literature.

Overall, the precision of the HPV methods was an average $R^{2}$ of 0.822 with the Sapflow+ method having the greatest precision of 0.986 (Table 1). The linear regression had an average slope of 0.860 with the Dual Heat Pulse Method having a slope closest to 1 with 1.071. The deviation of the slope was an average $34.706 \%$ with the HRM having the least deviation with an average of $16.949 \%$. These results suggest that the HPV methods have high precision but a bias towards underestimating true plant water use.

Table 1. A summary of descriptive statistics derived from the meta-analysis of research on the accuracy of HPV methods against an independent measurement of plant water use. Values for $R^{2}$, slope, and deviation from slope are means from the studies compiled in Supplementary Materials.

\begin{tabular}{ccccccc}
\hline Method & $\boldsymbol{n}$ & $\boldsymbol{R}^{\mathbf{2}}$ & Slope & $\begin{array}{c}\text { Deviation from } \\
\text { Slope }(\mathbf{\%})\end{array}$ & $\begin{array}{c}\text { Minimum } \\
\text { Range }(\mathbf{c m} / \mathbf{h})\end{array}$ & $\begin{array}{c}\text { Maximum } \\
\text { Range }(\mathbf{c m} / \mathbf{h})\end{array}$ \\
\hline All methods & 104 & 0.822 & 0.860 & 34.706 & & \\
T-max & 10 & 0.859 & 0.672 & 36.560 & 5 to 10 & $>200$ \\
CHPM & 59 & 0.723 & 0.863 & 30.611 & 2 to 5 & $>200$ \\
HRM & 11 & 0.916 & 0.833 & 16.949 & -10 & 45 \\
Sapflow+ & 7 & 0.986 & 0.620 & 38.000 & -10 & $>200$ \\
Dual & 17 & 0.892 & 1.071 & 59.706 & -10 & $>200$ \\
\hline
\end{tabular}




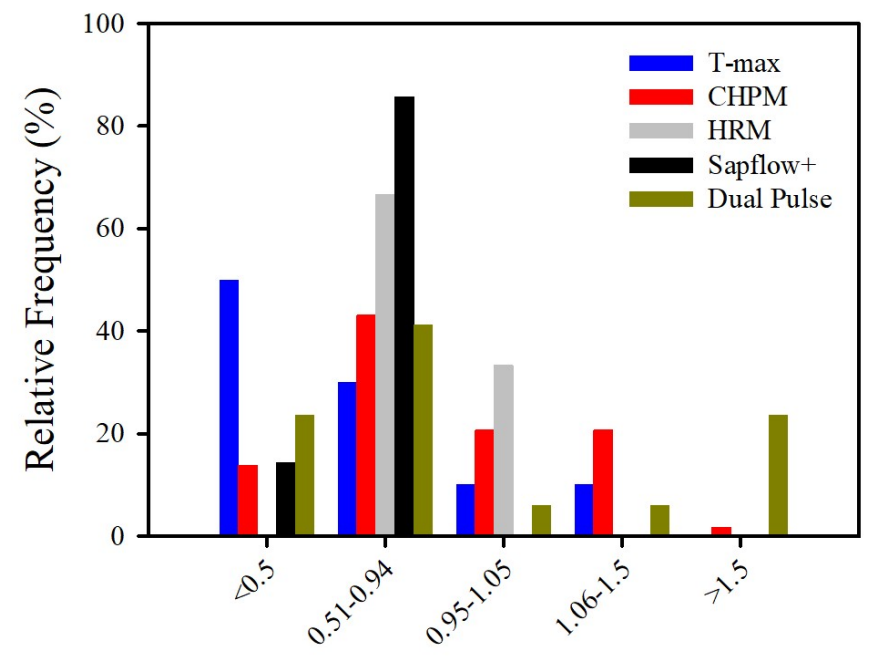

Linear Regression Slope

Figure 1. A relative frequency histogram of the slope of the regression curve from the studies compiled in the meta-analysis (Supplementary Materials). For easier comparison, slopes were grouped into different ranges where $<0.5$ indicates severe underestimation, 0.51 to 0.94 indicates moderate underestimation, 0.95 to 1.05 indicates good accuracy, 1.06 to 1.5 indicates moderate overestimation, and a slope $>1.5$ indicates severe overestimation of the HPV method for actual plant water use.

Figure 1 supports this result further by showing a histogram of the frequency of slopes within various groupings from the different HPV methods. Only a small proportion of studies had a slope within the range of 0.95 to 1.05 - or within $5 \%$ of true plant water use. The T-max and Sapflow+ methods were bias towards underestimating true plant water use whereas there was a large variation in the results from the dual method.

The results from Table 1 and Figure 1 possibly suggest where the HPV methods are inaccurate in measuring true plant water use. All HPV methods are precise and reproducible therefore the methods are excellent at correlating thermal conductance and convection with rates of water use in plants. However, all HPV methods are inaccurate, with a large deviation from the slope, which suggests there are problems with converting heat velocity into sap velocity, sap flow, and total plant water use.

\section{Sources of Error}

\subsection{Measurement Range}

A major difference between HPV methods is their limited measurement range (Table 1). The CHPM and T-max methods cannot measure slow or reverse flows [16] and the HRM cannot measure high flows [25]. The Sapflow+ and Dual Pulse methods can measure a wide range of flows $[14,19]$.

A limited measurement range means that transpiration over a certain period of the day will not be recorded. For example, approximately $12 \%$ of sap flow occurs at night under slow flow conditions [26] which the CHPM and T-max methods may not be able to measure [27]. High rates of sap flow or transpiration occur during the middle of the day and the HRM cannot measure such flows [19]. During such periods, measurements from HRM sensors will not be missing, rather there will be a plateau, or even decline, in heat velocity [19]. The limited measurement range of respective HPV methods is potentially a significant source of error. 


\subsection{Probe Misalignment}

During sensor installation, it is common for the temperature probes to be installed at a slight angle to the heater probe. Despite guides, it is almost impossible to install probes exactly parallel. Probe misalignment can lead to large errors as HPV calculations are highly sensitive to the distance between the heater and the probes. For example, an error in spacing of $2 \mathrm{~mm}$ led to a $100 \%$ error in sap velocity estimations for a potted tree sapling, Eucalyptus marginata, with a HRM based sensor [15]. Additionally, the placement of HPV sensors requires the heater and downstream and upstream probes to be installed in a common virtual plane parallel to axial flow direction in the xylem. This condition can also be difficult to achieve with perfect accuracy because of either lateral probe misalignments or difficulties associated to 'no vertical' sap flow ascent (e.g., species with convolute xylem); and is far more challenging to correct. Generally, probe misalignment can lead to either an over or underestimation of transpiration.

HPV methods that have fewer probes, such as the T-max method, will have less chance of errors associated with probe misalignment. For other methods, correcting for probe misalignment is achieved by applying a correction to the data set [12]. This requires establishing a zero-flow offset by noting the value when sap flow should be zero and applying this value to the sap flow data set. A period of zero sap flow can be artificially induced by cutting the stem below the sensor. Where this destructive approach is not possible, zero sap flow will occur during periods when there is no biophysical driving force. Such a condition is met at pre-dawn when soil moisture is saturated or at field capacity and when atmospheric vapor pressure deficit is zero. Alternatively, Ren et al. [28] proposed a method for in situ correction of probe misalignment. Although probe misalignment is likely the most common source of error associated with sap flow measurements [12], it is easily corrected and should not impact overall estimates of plant water use.

\subsection{Wounding}

Wounding of xylem tissue is a significant source of error in sap flow measurements. Wounding is caused by drilling and insertion of probes into living plant tissue. The drill hole is part of the wound and the plant can respond to drilling by forming tyloses [29]. Wounding can lead to underestimation of actual sap velocity by between $50 \%$ and $90 \%$ [16,30].

Although the issue of wounding is widely recognized, accurate measurement and corrections for wounding often lacks rigor. For example, a common approach is to measure the wound width at the end of a measurement campaign. However, wounding is dynamic and should be measured periodically throughout the campaign (e.g., [31]). The magnitude of wound is unpredictable and is dependent on individual plants, stem anatomy, and/or drilling technique during probe installation. Therefore, periodic observation and measurement of the wound is required.

Wound correction factors are available to convert heat velocity $\left(V_{h}\right)$ to corrected heat velocity $\left(V_{c}\right)$. Correction factors for wounding can be created for specific species, probe materials, or HPV method. The procedure for determining wound correction factors is, however, highly complex and involves finite-difference numerical modelling [30]. Many studies rely on published tables that list correction factors for T-max, CHPM, and HRM [12,16,30,32]. Further research is required to determine the generality of these published correction factors and how they may influence estimates of sap flow and transpiration. However, current evidence suggests that wound width has a much larger effect than probe material, so calibration factors based only on wound width are expected to be sufficient for a given sensor configuration [16,30].

\subsection{Thermal Diffusivity or Conductivity}

HPV methods are based on theoretical models of thermal convection and conductance/diffusivity of materials. In xylem, thermal convection is the sap movement and thermal diffusivity is the 'natural' movement of heat through cell walls, intercellular space, and fluids. For the CHPM, thermal diffusivity 
is compensated via the probe configuration whereas thermal diffusivity must be explicitly estimated for the T-max, HRM, and Sapflow+ methods [9].

Many studies, particularly those employing HRM, use Marshall's [11] default thermal diffusivity value of $2.5 \times 10^{-3} \mathrm{~cm}^{2} \cdot \mathrm{s}^{-1}$ (e.g., [33]). Other studies that do measure thermal diffusivity only do so once typically at the end of a measurement campaign (e.g., [34]). However, thermal diffusivity can vary significantly from the default value and throughout the measurement period [35]. Consequently, miscalculations of thermal diffusivity can lead to errors in heat and sap velocity calculations and, subsequently, either an over or underestimation of transpiration.

Various methods are available to measure thermal diffusivity or conductivity in plant stems. For example, the T-max method calculates thermal diffusivity when there is zero sap flow [13] and the method has been improved upon [36]. Looker et al. [35] performed an in-depth review of thermal diffusivity methods and recommended the method of Vandegehuchte and Steppe [37] for HPV studies.

\subsection{Stem Moisture Content}

Probe misalignment, wounding, and thermal diffusivity influence $V_{c}$. Once this parameter has been calculated, it is necessary to convert $V_{c}$ to sap velocity $\left(J_{v}\right)$ which requires the addition of stem properties such as moisture content and wood density $[29,38]$ :

$$
J_{v}=\frac{V_{C} \rho_{b}\left(C_{w}+m_{c} C_{s}\right)}{\rho_{s} C_{s}}
$$

where $\rho_{b}$ and $\rho_{s}$ are the basic density of wood and water, respectively, $C_{w}$ and $C_{s}$ are the specific heat capacity of wood and sap, respectively, and $m_{c}$ is sapwood moisture content. The parameters $\rho_{s}, C_{w}$, and $C_{s}$ are constants whereas $\rho_{b}$ and $m_{c}$ need to be measured and are commonly measured once at the end of a campaign (e.g., [39]). Although $\rho_{b}$ does not vary throughout the measurement period, $m_{c}$ can change up to $70 \%$ on a daily and seasonal basis $[14,40,41]$. An incorrect measurement of $m_{c}$ can lead to either an over or underestimation of transpiration.

Typically, the dynamic nature of $m_{c}$ is ignored in sap flow and transpiration calculations. Errors in $m_{c}$ estimates were shown to lead to a 7\% to 9\% error in Fagus grandifolia and Populus tremuloides $J_{v}$ estimates via a HRM and CHPM sensor, respectively $[42,43]$. However, in recent years greater attention has been given to accurate and dynamic measurements of $m_{\mathcal{c}}$ [44]. Importantly, it is increasingly recognized that HPV sensors can simultaneously measure sap flow and $m_{\mathcal{c}}$ (e.g., [14,40]).

\subsection{Sapwood Radial and Azimuthal Variability}

Once $J_{v}$ has been calculated, whole plant sap flow $(Q)$ can be estimated by the multiplication of $J_{v}$ by the conducting xylem area $(A)[12]$ :

$$
Q=J_{v} A
$$

There are several potential significant sources of error in this simple calculation. For example, sapwood area can be difficult to measure accurately due to heterogenous tree structure. Additionally, the transitional zone between conducting (sapwood) and non-conducting (heartwood) xylem can be ambiguous with different measurement techniques yielding different results [45]. In some studies, the sampled tree cannot be measured due to its heritage or inherent value and sapwood area must be estimated by measuring nearby trees or from allometric equations.

Another significant source of error is not correctly measuring radial and azimuthal sap flow. The amount of sap flow varies between the outside and inside of the sapwood where, typically, sap flow is highest towards the outside [46]. Sensors that only have a single measurement point along the radial profile will either under or overestimate total sap flow therefore multi-point probes will improve accuracy [46,47].

Sap flow also differs around the circumference of the tree due to the sapwood variability [46]. The number of sampling points required to adequately capture radial and azimuthal $J_{v}$ variations is 
difficult to determine. However, there have been efforts to estimate the optimal number of sampling points. For example, Dye et al. [48] estimated that a minimum of 12 sampling points will be required for pine trees with a stem diameter between 12 and $22 \mathrm{~cm}$. Other researchers have developed models to estimate radial patterns of $J_{v}$ (e.g., $[47,49]$ ). Adequate sapwood sampling, combined with rigorous models, will lead to accurate estimates of $Q$ from $J_{v}$ point measurements.

\subsection{Measurement Zone of Influence and Positioning of Sensors}

HPV sensors measure sap velocity dynamics at a single point, or measurement zone, in the xylem tissue. However, there has been little research on the actual radius of this point. The best estimates are between a 0.3 and $0.5 \mathrm{~cm}$ radius [11,50-52]. Extreme caution, then, needs to be taken when extrapolating $V_{c}$ and $J_{v}$ to $Q$ from the small area measured by a single point temperature sensor, particularly in large trees.

If the measurement zone of a temperature sensor is taken as a conservative $0.5 \mathrm{~cm}$ radius, then sensors positioned within $<0.5 \mathrm{~cm}$ from the bark, phloem or heartwood are potentially measuring thermal dynamics of non-conducting plant tissue. Temperature sensors may also be positioned on the boundaries between early and late season wood. How these sensor positions affect HPV estimates is not known. However, Dye et al. [48] noted that HPV was higher in summer wood versus winter wood in Pinus patula. Temperature sensor positions proximal to bark or heartwood will most likely underestimate HPV. Positioning of sensors in species with ring-porous or diffuse-porous xylem anatomies should also be considered carefully for accurate estimates of total sap flow and transpiration [53].

\section{Discussion}

This review highlighted that a commonly used approach to estimate transpiration, HPV sap flow sensors, had an average error of $34.706 \%$. Although some studies did accurately estimate transpiration, there was a tendency for HPV methods to underestimate transpiration.

Although this review focused on the HPV family of sap flow methods it was not intended to demonstrate that this method is inherently flawed and that alternative sap flow methods are superior. Another popular sap flow method, the thermal dissipation or Granier method, has also been demonstrated to underestimate transpiration with as much, or more, error than HPV methods $[9,24,43]$. Rather, this review is a caution to scientists to not rely on theoretical calculations of transpiration from HPV or any sap flow method. If an estimation of transpiration is the aim of a study, HPV sap flow sensors can certainly be deployed, but they must be carefully calibrated [21,43]. Any study that presents transpiration data from uncalibrated sap flow sensors should be regarded with extreme caution.

Recently, there has been considerable research on improving HPV methods through refining theoretical approaches, or the proposal of empirical or practical based approaches. For example, a newly proposed theoretical method, the single-probe heat pulse (SPHP) method, requires only a single probe rather than the traditional two or three probe configurations [54]. The SPHP will improve errors associated with probe misalignment. However, it still has a limited measurement range, similar to the CHPM, and is impractical at slow or reverse flow. The empirical gradients methods, such as the calibrated averaged gradients method [55], the symmetrical gradient method or the maximum derivative method [56] aims to extend the limited measurement ranges of T-max, CHPM, and HRM. These empirical methods have been shown to excellent in extending the limited measurement range of T-max, CHPM, and HRM. However, these alternative methods do not improve overall accuracy of transpiration estimates as they are still encumbered by sources of error discussed above. HPV methods have been demonstrated to have an excellent correlation with relative changes in transpiration but cannot accurately estimate the amount of transpiration. Currently, existing and newly proposed methods have not improved the accuracy of transpiration estimates. Greater accuracy will be achieved by improving dynamic measurements of wounding, stem moisture content and wood thermal diffusivity $[9,35]$. The appropriate placement of sensors in sapwood is also critical. 
For example, Pearsall et al. [19] noted the high variability in the accuracy of the Dual Heat Pulse Method was largely due to the difficulties in accurate placement of HPV sensors in the sapwood of grapevines.

Sap flow sensors can still reliably be deployed without the need for calibration depending on the application. Relative rates of sap flow, or correlated sap flow responses to biotic or abiotic variables, do not necessarily require calibrated sensors. For example, Doronila and Forster [57] demonstrated how peak diurnal sap flow differed across three co-occurring Eucalyptus species in response to heat waves, vapor pressure deficit (VPD), and temperature. Burgess and Dawson [58] used normalized sap flow rates to determine the capacitance of trees. In these and similar studies, the relative, directional rate, or timing of sap flow was of primary interest and negated the need for sensor calibration.

\section{Conclusions}

Sap flow sensors are a low-cost and practical option to measure tree transpiration. However, there remain significant errors with theoretical and empirical equations that aim to directly estimate transpiration from thermal based measurements. The heat pulse velocity based methods are excellent in correlating relative changes in transpiration rates but exhibit large errors in estimating amounts of transpiration. Where whole plant water use or the amount of transpiration is of primary interest, sap flow sensors must be calibrated.

Supplementary Materials: The following are available online at www.mdpi.com/link/1999-4907/8/9/350/s1. Acknowledgments: M.A.F. acknowledges the three reviewers for their constructive comments that significantly improved the manuscript.

Conflicts of Interest: The author declares no conflict of interest. M.A.F. is a Director of Edaphic Scientific Pty Ltd. that is a commercial company supplying a range of sap flow sensors.

\section{References}

1. Forster, M.A. Quantifying water use in a plant-fungal interaction. Fungal Ecol. 2012, 5, 702-709. [CrossRef]

2. Jara, J.; Stockle, C.O.; Kjelgaard, J. Measurement of evapotranspiration and its components in a corn (Zea mays L.) field. Agric. For. Meteorol. 1998, 92, 131-145. [CrossRef]

3. Vertessy, R.; Watson, F.; O'Sullivan, S.; Davis, S.; Campbell, R.; Benyon, R.; Haydon, S. Predicting Water Yield from Mountain Ash Forest Catchments; Cooperative Research Centre for Catchment Hydrology Industry Report 98/4; Monash: Victoria, Australia, 1998.

4. Kohnke, H.; Dreibelbis, F.R.; Davidson, J.M. A Survey and Discussion of Lysimeters and a Bibliography on Their Construction and Performance; Misc. Publ. No. 372; U.S. Department of Agriculture: Washington, DC, USA, 1940.

5. Van Bavel, C.H.M.; Nakayama, F.S.; Ehrler, W.L. Measuring transpiration resistance of leaves. Plant Physiol. 1965, 40, 535-540. [CrossRef] [PubMed]

6. Huber, B. Beobachtung und Messung pflanzlicher Saftstr6me. Ber. Deutsch. Bot. Ges. 1932, 50, 89-109.

7. Smith, D.M.; Allen, S.J. Measurement of sap flow in plant stems. J. Exp. Bot. 1996, 47, 1833-1844. [CrossRef]

8. Raven, P.H.; Evert, R.F.; Eichhorn, S.E. Biology of Plants, 6th ed.; W.H. Freeman and Company: New York, NY, USA, 1999.

9. Vandegehuchte, M.W.; Steppe, K. Sap-flux density measurement methods: Working principles and applicability. Funct. Plant Biol. 2013, 40, 213-223. [CrossRef]

10. Swanson, R.H. An Instrument for Detecting Sap Movement in Woody Plants; Station Paper 68; USDA Forest Service, Rocky Mountain Forest and Range Experiment Station: Fort Collins, CO, USA, 1962.

11. Marshall, D.C. Measurement of sap flow in conifers by heat transport. Plant Physiol. 1958, 33, 385-396. [CrossRef] [PubMed]

12. Burgess, S.S.O.; Adams, M.A.; Turner, N.C.; Beverly, C.R.; Ong, C.K.; Khan, A.A.H.; Bleby, T.M. An improved heat pulse method to measure low and reverse rates of sap flow in woody plants. Tree Physiol. 2001, 21, 589-598. [CrossRef] [PubMed]

13. Cohen, Y.; Fuchs, M.; Green, G.C. Improvement of the heat pulse method for determining sap flow in trees. Plant Cell Environ. 1981, 4, 391-397. [CrossRef] 
14. Vandegehuchte, M.W.; Steppe, K. Sapflow+: A four-needle heat-pulse sap flow sensor enabling nonempirical sap flux density and water content measurements. New Phytol. 2012, 196, 306-317. [CrossRef] [PubMed]

15. Bleby, T.M.; Burgess, S.S.O.; Adams, M.A. A validation, comparison and error analysis of two heat-pulse methods for measuring sap flow in Eucalyptus marginata saplings. Funct. Plant Biol. 2004, 31, 645-658. [CrossRef]

16. Green, S.; Clothier, B.; Jardine, B. Theory and practical application of heat pulse to measure sap flow. Agron. J. 2003, 95, 1371-1379. [CrossRef]

17. Green, S.; Clothier, B.; Perie, E. A re-analysis of heat pulse theory across a wide range of sap flows. Acta Hort. 2009, 846, 95-104. [CrossRef]

18. Jones, H.G.; Hamer, P.J.C.; Higgs, K.H. Evaluation of various heat-pulse methods for estimation of sap flow in orchard trees: Comparison with micrometeorological estimates of evaporation. Trees 1988, 2, 250-260. [CrossRef]

19. Pearsall, K.R.; Williams, L.E.; Castorani, S.; Bleby, T.M.; McElrone, A.J. Evaluating the potential of a novel dual heat-pulse sensor to measure volumetric water use in grapevines under a range of flow conditions. Funct. Plant Biol. 2014, 41, 874-883. [CrossRef]

20. Ballester, C.; Castel, J.; Sanz, F.; Yeves, A.; Intrigliolo, D.S.; Castel, J.R. Can sap flow be used for determining transpiration of citrus trees under different irrigation regimes? Acta Hort. 2011, 922, 221-228. [CrossRef]

21. Dragoni, D.; Lakso, A.N.; Piccioni, R.M. Transpiration of apple trees in a humid climate using heat pulse sap flow gauges calibrated with whole-canopy gas exchange chambers. Agric. For. Meterol. 2005, 130, 85-94. [CrossRef]

22. Zeppel, M.J.B.; Lewis, J.D.; Medlyn, B.; Barton, C.V.M.; Duursma, R.A.; Eamus, D.; Adams, M.A.; Phillips, N.; Ellsworth, D.S.; Forster, M.A.; et al. Interactive effects of elevated $\mathrm{CO}_{2}$ and drought on nocturnal water fluxes in Eucalyptus saligna. Tree Physiol. 2011, 31, 932-944. [CrossRef] [PubMed]

23. Prendergast, P.T.; Astill, M.S.; Green, S.R.; Mills, T.M.; Clothier, B.E. Water use by a kiwifruit vine: Calibration, measurement and a model. Acta Hort. 2007, 753, 535-538. [CrossRef]

24. Fuchs, S.; Leuschner, C.; Link, R.; Coners, H.; Schuldt, B. Calibration and comparison of thermal dissipation, heat ratio and heat field deformation sap flow probes for diffuse-porous trees. Agric. For. Meteorol. 2017, 244-245, 151-161. [CrossRef]

25. Bleby, T.M.; McElrone, A.J.; Burgess, S.S.O. Limitations of the HRM: Great at low flow rates, but no yet up to speed? In Proceedings of the 7th International Workshop on Sap Flow: Book of Abstracts, Seville, Spain, 21-24 October 2008; International Society of Horticultural Sciences: Seville, Spain, 2008.

26. Forster, M.A. How significant is nocturnal sap flow? Tree Physiol. 2014, 34, 757-765. [CrossRef] [PubMed]

27. Benyon, R.G. Nighttime water use in an irrigated Eucalyptus grandis plantation. Tree Physiol. 1999, 19, 853-859. [CrossRef] [PubMed]

28. Ren, R.; Liu, G.; Wen, M.; Horton, R.; Li, B.; Si, B. The effects of probe misalignment on sap flux density measurements and in situ probe spacing correction methods. Agric. For. Meteorol. 2017, 232, 176-185. [CrossRef]

29. Barrett, D.J.; Hatton, T.J.; Ash, J.E.; Ball, M.C. Evaluation of the heat pulse velocity technique for measurement of sap flow in rainforest and eucalypt forest species of south-eastern Australia. Plant Cell Environ. 1995, 18, 463-469. [CrossRef]

30. Swanson, R.H.; Whitfield, D.W.A. A numerical analysis of heat pulse velocity and theory. J. Exp. Bot. 1981, 32, 221-239. [CrossRef]

31. Bleby, T.M.; McElrone, A.J.; Jackson, R.B. Water uptake and hydraulic redistribution across large woody root systems to $20 \mathrm{~m}$ depth. Plant Cell Environ. 2010, 33, 2132-2148. [CrossRef] [PubMed]

32. Green, S.R.; Clothier, B.E. Water use of kiwifruit vines and apple trees by the heat-pulse technique. J. Exp. Bot. 1988, 39, 115-123. [CrossRef]

33. Zhao, C.Y.; Si, J.H.; Qi, F.; Yu, T.F.; Li, P.D. Comparative study of daytime and nighttime sap flow of Populus euphratica. Plant Growth Regul. 2017, 82, 353-362. [CrossRef]

34. Deng, Z.; Guan, H.; Hutson, J.; Forster, M.A.; Wang, Y.; Simmons, C.T. A vegetation focused soil-plant-atmospheric continuum model to study hydrodynamic soil-plant water relations. Water Resour. Res. 2017, 53, 4965-4983. [CrossRef]

35. Looker, N.; Martin, J.; Jencso, K.; Hu, J. Contribution of sapwood traits to uncertainty in conifer sap flow as estimated with the heat-ratio method. Agric. For. Meteorol. 2016, 223, 60-71. [CrossRef] 
36. Kluitenberg, G.J.; Ham, J.M. Improved theory for calculating sap flow with the heat pulse method. Agric. For. Meteorol. 2004, 126, 169-173. [CrossRef]

37. Vandegehuchte, M.W.; Steppe, K. Improving sap flux density measurements by correctly determining thermal diffusivity, differentiating between bound and unbound water. Tree Physiol. 2012, 32, 930-942. [CrossRef] [PubMed]

38. Becker, P.; Edwards, W.R.N. Corrected heat capacity of wood for sap flow calculations. Tree Physiol. 1999, 19, 767-768. [CrossRef] [PubMed]

39. Pfautsch, S.; Keitel, C.; Turnbull, T.; Braimbridge, M.J.; Wright, T.E.; Simpson, R.R.; O’Brien, J.A.; Adams, M.A. Diurnal patterns of water use in Eucalyptus victrix indicate pronounced desiccation-rehydration cycles despite unlimited water supply. Tree Physiol. 2011, 31, 1041-1051. [CrossRef] [PubMed]

40. López-Bernal, A.; Testi, L.; Villalobos, F.J. Using the compensated heat pulse method to monitor trends in stem water content in standing trees. Tree Physiol. 2012, 32, 1420-1429. [CrossRef] [PubMed]

41. Renner, M.; Hassler, S.K.; Blume, T.; Weiler, M.; Hildebrandt, A.; Guderle, M.; Schymanski, S.J.; Kleidon, A. Dominant controls of transpiration along a hillslope transect inferred from ecohydrological measurements and thermodynamic limits. Hydrol. Earth Syst. Sci. 2016, 20, 2063-2083. [CrossRef]

42. Hogg, E.H.; Black, T.A.; den Hartog, G.; Neumann, H.H.; Zimmermann, R.; Hurdle, P.A.; Blanken, P.D.; Nesic, Z.; Yang, P.C.; Staebler, R.M.; et al. A comparison of sap flow and eddy fluxes of water vapor from a boreal deciduous forest. J. Geophys. Res. 1997, 102, 28929-28937. [CrossRef]

43. Steppe, K.; De Pauw, D.J.W.; Doody, T.M.; Teskey, R.O. A comparison of sap flux density using thermal dissipation, heat pulse velocity and heat field deformation methods. Agric. For. Meteorol. 2010, 150, 1046-1056. [CrossRef]

44. Matheny, A.M.; Bohrer, G.; Garrity, S.R.; Morin, T.H.; Howard, C.J.; Vogel, C.S. Observations of stem water storage in trees of opposing hydraulic strategies. Ecosphere 2015, 6, 1-13. [CrossRef]

45. Pfautsch, S.; Macfarlane, C.; Ebdon, N.; Meder, R. Assessing sapwood depth and wood properties in Eucalyptus and Corymbia spp. using visual methods and near infrared spectroscopy (NIR). Trees 2012, 26, 963-974. [CrossRef]

46. Čermák, J.; Kučera, J.; Nadezhdina, N. Sap flow measurements with some thermodynamic methods, flow integration within trees and scaling up from sample trees to entire forest stands. Trees 2004, 18, 529-546. [CrossRef]

47. Alvarado-Barrientosa, M.S.; Hernández-Santana, V.; Asbjornsen, H. Variability of the radial profile of sap velocity in Pinus patula from contrasting stands within the seasonal cloud forest zone of Veracruz, Mexico. Agric. For. Meteorol. 2013, 168, 108-119. [CrossRef]

48. Dye, P.J.; Olbrich, B.W.; Poulter, A.G. The influence of growth rings in Pinus patula on heat pulse velocity and sap flow measurements. J. Exp. Bot. 1991, 42, 867-870. [CrossRef]

49. Berdanier, A.B.; Miniat, C.F.; Clark, J.S. Predictive models for radial sap flux variation in coniferous, diffuse-porous and ring-porous temperate trees. Tree Physiol. 2016, 36, 932-941. [CrossRef] [PubMed]

50. Smith, R.E. The heat pulse velocity technique for determining water uptake of Populus deltoides. S. Afr. J. Bot. 1992, 58, 100-104. [CrossRef]

51. Swanson, R.H. Velocity distribution patterns in ascending xylem sap during transpiration. In Flow-Its Measurement and Control in Science and Industry; Dowdell, R.B., Ed.; Instrument Society of America: Pittsburgh, PA, USA, 1974; pp. 1425-1430.

52. Swanson, R.H. Significant historical developments in thermal methods for measuring sap flow in trees. Agric. For. Meteorol. 1994, 72, 113-132. [CrossRef]

53. Phillips, N.; Oren, R.; Zimmerman, R. Radial patterns of xylem sap flow in non-, diffuse- and ring-porous tree species. Plant Cell Environ. 1996, 983, 983-990. [CrossRef]

54. López-Bernal, A.; Testi, L.; Villalobos, F.J. A single-probe heat pulse method for estimating sap velocity in trees. New Phytol. 2017. [CrossRef]

55. Testi, L.; Villalobos, F.J. New approach for measuring low sap velocities in trees. Agric. For. Meteorol. 2009, 149, 730-734. [CrossRef]

56. Green, S.R.; Romero, R. Can we improve heat-pulse to measure low and reverse flows? Acta Hort. 2012, 951, 19-30. [CrossRef] 
57. Doronila, A.I.; Forster, M.A. Performance measurement via sap flow monitoring of three Eucalyptus species for mine site and dryland salinity phytoremediation. Int. J. Phytoremediat. 2015, 17, 101-108. [CrossRef] [PubMed]

58. Burgess, S.S.O.; Dawson, T.E. Using branch and basal trunk sap flow measurements to estimate whole-plant water capacitance: A caution. Plant Soil 2008, 305, 5-13. [CrossRef] 